\title{
Research on High-efficient Balcony Greening Based on the Concept of Low-carbon Green Buildings
}

\author{
Jinkun Sun ${ }^{1,2, a *}$, Jing Liu ${ }^{1,2, b}$, Feng Wu ${ }^{1,2, c}$, Hongfen Nian ${ }^{1,2, d}$ \\ ${ }^{1}$ School of Civil and Architecture Engineering, Panzhihua University, Panzhihua 617000, \\ Sichuan, China \\ ${ }^{2}$ Institute of Engineering Structure, Panzhihua University, Panzhihua 617000, Sichuan, China \\ apaxf66290838@163.com, b327080461@qq.com, '378231703@qq.com, d840603656@qq.com
}

\begin{abstract}
Keywords:Low-carbon green buildings, Efficiency, Balcony greening, Effect analysis
Abstract. The design of Low-carbon Green Buildings emphasizes the application of eco-friendly strategies in buildings while paying close attention to their images, with the purpose of dealing with the relationship among buildings, environment and ecology, and realizing a benign cycle between factors of the artificial environment and those of the natural environment. The efficient greening of buildings' balconies is an important link of realizing the concept of Low-carbon Green Buildings. This passage puts forward highly effective solutions regarding balcony greening from the periods of design and usage. It analyzes the greening effect of highly effective greening balconies on temperature and humidity of buildings, concentration of $\mathrm{CO}_{2}$, noise reduction and other indexes, and proposes forecasts to the development and design of balcony greening in the future.
\end{abstract}

\section{Introduction}

It is one of the goals of the Low-carbon Green Buildings to create an environment close to the nature for the people living in it. Low-carbon Green Buildings which are leading the development direction of modern housing play a dominant role in the future development of the real estate industry[1]. China, a country with the largest population in the world and a great demand for housing, is the largest construction market in the world. Because the building energy consumption per unit of area is relatively high, the total building energy consumption is amazingly high; meanwhile, more than $95 \%$ of the buildings in our country is of high energy consumption. With the rapid development of the economy and the increasing living standard of people, the building energy consumption in our country will increase continuously, and it may become the point of growth of the main energy consumption in the next two decades[2].

The current low-carbon greening of buildings mainly uses the "passive design".The adopted methods are various, including installing heat insulation materials and using new-type energy (namely, solar energy) and more energy-saving and environmentally-friendly air-conditioners in buildings, and planting green plants on indoor windowsills, and in living rooms and balconies in order to maintain the indoor temperature, reduce indoor noise and purify the air. These measures have played an important role in the formation of Low-carbon Green Buildings, but Low-carbon Green Buildings should run through the whole life cycle from design and construction of buildings to the end of their service life, embodying the architectural development pattern of "recyclability and sustainability" from energy conservation of buildings to the development of green buildings[3].The design of buildings' indoor greening plays an important role in the recyclable and sustainable development. Balcony greening, as an imperative aspect of buildings' indoor greening, has a crucial influence on the effect of indoor greening. Currently, there are such problems as low integration of building design, inefficiency of plantation and low levels of greening in balcony greening, and this passage studies and probes into how to realize efficient balcony greening of buildings. 


\section{Design and Analyses of Balcony Greening}

\section{The Proportion of Balcony Greening in Interior Design}

It is found after the analysis of the findings of the survey concerning the greening areas in 200 family flats with different house types in Panzhihua City that people have spent a lot of time on greening for a long time, but the effect is poor, that indoor greening is mainly carried out by buying pot plants, and that balconies, which occupy the largest proportion of greening, are dominated by self-planted plants, with low efficiency and relatively bad quality of plant greening. The proportion analysis of the space in the building which can be used in interior greening design is shown in Table 1.

Table 1 Residential green area

\begin{tabular}{cccccc}
\multicolumn{1}{c}{ Table 1 Residential green area } & & Unit: $\mathrm{m}^{2}$ \\
\hline $\begin{array}{c}\text { areening } \\
\text { parts }\end{array}$ & $\begin{array}{c}\text { arelow } \\
75 \mathrm{~m}^{2}\end{array}$ & $75-100 \mathrm{~m}^{2}$ & $100-125 \mathrm{~m}^{2}$ & $125-150 \mathrm{~m}^{2}$ & $\begin{array}{c}\text { above } \\
150 \mathrm{~m}^{2}\end{array}$ \\
\hline bedroom & 0 & 0.1 & 0.1 & 0.2 & $>0.2$ \\
\hline windowsill & 0.2 & 0.3 & 0.3 & 0.3 & 0.5 \\
\hline sitting room & 0.1 & 0.2 & 0.3 & 0.5 & 0.5 \\
\hline balcony & 0 & 0.5 & 1.2 & 1.5 & $>1.5$ \\
\hline other & 0 & 0.1 & 0.2 & 0.2 & $>0.2$ \\
\hline
\end{tabular}

It can be indicated from the analysis of the survey data in Table 1 that the per-unit residential green area increases along with the increase of the residential area and the balcony greening accounts for 50\% of the total greening area. It can be concluded that the low-carbon greening design should focus on the balcony.

\section{A High-efficient Solution to Balcony Greening in the Design Period}

Aiming at the problems existing in the greening of building balconies, a more high-efficient solution is specially put forward to balcony greening from the architectural design to later use.

Design of building orientations. The balcony should have the characteristic of providing adequate sunlight and agreeable indoor air circulation for plants. Therefore, in our design we can rely on the angle of sunshine and sunlight incidence to settle the direction scope of the building, and further turn to seasonal winds for the coordination and selection of reasonable orientations.

Innovative balcony design.In the architectural design, plant slots (plane type and three-dimensional type) are added to the balcony in advance, and in water and electricity installation design, water for balcony plants should be considered sufficiently. The measures such as adding planting hanging nets on the balcony wall are to help households to perform the standardized cultivation so as to improve the effective planting rate of plants.

High-efficiency greening design. Expanding the size of the balcony while at the same time setting a planting slot at the window of the balcony [4] and adding a plant balcony in order to provide more green space and better green effects and further expand the influencing range of the green balcony.

\section{The High-efficiency Solution to Balcony Greening of Constructed Residences}

For those constructed residences without the implementation of the high-efficient balcony greening design, the balcony greening efficiency can be increased through scientifically reasonable arrangements. The detailed plan is as follows:

Properly select the plant variety. The different orientation of balconies leads to a huge difference on the length of illumination time and the illumination intensity for such plants as flowers and vegetables, so it should be considered to choose the proper plant variety.

Scientific layout.Green plants on the balcony are laid in the layout by adopting the combination of plane, three-dimensional and wall-attached methods, thus utilizing balcony space to the maximum 
extend. The stereo type selects appropriate areas, in which two or more layers of plants will be planted; the wall-attached type adds handing racks to balcony walls, making plants in the shape of rattan fully cover the walls.

Adopting advanced plant cultivation techniques. So far, four types of soilless cultivation devices for family garden balcony have been developed, namely the column type, the ladder type, the wall-attached type and the pumpkin type. All of them are composed of cultivation conduit (container), nutrient solution box, perfusion tube and the holder.Additionally, the application of soilless cultivation in balcony greening is mature [5], providing a strong guarantee for the high-efficiency of balcony greening.

\section{The High-efficiency Solution to Balcony Greening of Constructed Residences}

Under the same condition of the building orientations, environment temperatures, balcony types, plant varieties and nutrition rations, a contrast test of the humidity and temperatures of balconies was carried out between balconies of standard balcony greening and ordinary balconies. Three measurements of related parameters were carried out respectively. Taking average value, the result of the measurement data is shown in Fig. 1 and Fig. 2.

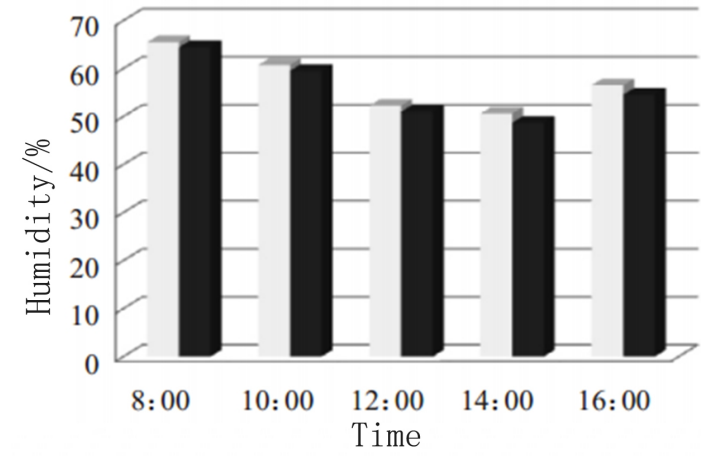

Fig. 1 The comparison of humidity "efficient green balcony - general balcony

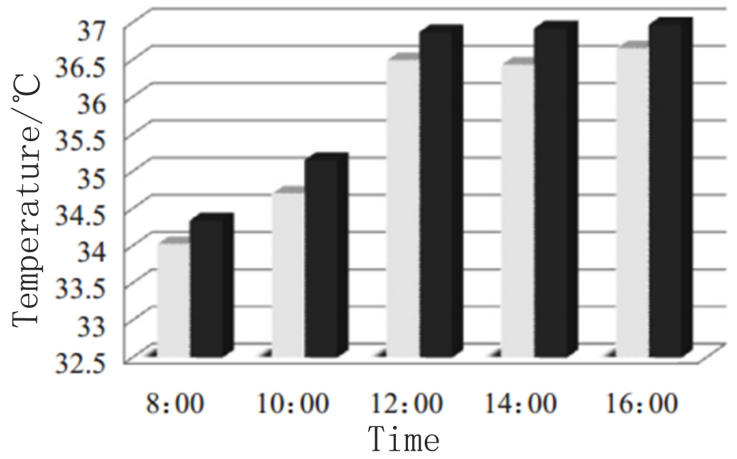

Fig. 2 The comparison of temperature

Through the comparison between Figure 1 and Figure 2, it can be found that:

High-efficiency Green Balcony in the room has effects of lowering the temperature and moistening on the indoor thermal environment; At different times and different heights of the room, the temperature of every section in the room of High-efficiency Green Balcony is $0.1 \sim 1.0^{\circ} \mathrm{C}$ lesser than that of the room with an ordinary green balcony, and their relative humidity is $0.1 \% \sim 3.6 \%$ higher than that of the room with an ordinary green balcony; The average temperature of the room with an High-efficiency Green Balcony is about $0.4^{\circ} \mathrm{C}$ lower, and its average relative humidity is about $1 \%$ to $2 \%$ higher than those of the the room with an ordinary green balcony.

According to the air quality detector's contrast detection of the room with a High-efficiency Green Balcony and the room with an ordinary balcony, the $\mathrm{CO}_{2}$ concentration of the former decreased significantly. After high-efficiency balcony greening, the indoor formaldehyde concentration decreased by $0.026 \mathrm{mg} / \mathrm{m}^{3}$, and formaldehyde pollution was thus substantially improved. Therefore, it will exert greater influence on the improvement of air quality through High-efficiency Green Balcony.

High-efficiency balcony greening plays a significant role in lowering noises. When the sound wave meets the green belt, it may be absorbed and reflected, and it may also continues to spread after bypassing the obstacle, that is to say, diffraction for continuous spread. So High-efficiency Green Balcony achieves the best effect of decreasing noises by increasing the width of plant belt and adopting the vertical arrangement.

\section{The Development Prospect of Balcony Greening in Future Architectures}

The design of future architecture will give more consideration to the function of balcony in low-carbon greening. By "initiative" design, it will take balcony greening as the essential element of design, laying 
a solid foundation for large-scale balcony greening in the future. The balcony greening function will be the highlight of real estate development.

The balcony greening brings not only low-carbon greening, but also more economic value to us. Nowadays, food safety becomes increasingly outstanding, and planting vegetables in the balcony will become an inevitable trend of development [5].Advances in technology and developments of integrated balcony planting machine and intelligent balcony plant controller bring more and more conveniences for our balcony lives. "Balcony Garden" lifestyle, which brings people' city lives with higher quality and more convinences, will inevitablly become the mainstream of the times' development.

\section{Conclusions}

The greening area of unit building increases with the increase of residential area, and the proportion of the balcony greening accounts for nearly $50 \%$ in the all greening. So the design of building's low-carbon greening focuses on the balcony.

Put forward Solution to Balcony Greening from the aspects of building orientation, innovative balcony, and high-efficiency design.

An efficient Solution to Balcony Greening in the built houses is put forward from three aspects of rational selection of plant species, scientific layout, and advanced plant cultivation techniques.

After the analysis of the greening effect, the highly active balcony greening has obvious effect of environmental protection on the temperature of buildings, humidity, the concentration of $\mathrm{CO}_{2}$ and noise reduction.

\section{References}

[1] Ming Lai.Development the green building,promoting the construction energy conservation and emissions reduction[J].Construction Science and Technology.2011(05) pp.16-17.[In Chinese].

[2] Jun qiang Liang,Hao Liang,Feng Zhang,etc.Development the green building industry, leading the green economic development[J].Construction Science and Technology.2012(17) pp.20-26.[In Chinese].

[3] Yike Wu.Study on design concept in low carbon energy saving buildings[J].Intelligence.2011(23) pp.36.[In Chinese].

[4] Luxiu Chai,Xun Zhang, Zhang Linfei.Analysis on the influence of energy saving on the development of building design[J].Temperature Architecture Technology.2008(03) pp.122-23.[In Chinese].

[5] Hua Cao,Shupo $\mathrm{Xu}$,Xinxu Li,etc.The balcony garden soilless cultivationdevice device and planting technology [J].China Vegetables 2011(19) pp.55-56.[In Chinese]. 